\title{
Pedagogical Evaluation of Digital Technology to Enhance Dental Student Learning
}

\author{
Camille Inquimbert ${ }^{1} \quad$ Paul Tramini $^{1} \quad$ Olivier Romieu $^{2} \quad$ Nicolas Giraudeau $^{1}$ \\ ${ }^{1}$ Departments of Dental Public Health, University of Montpellier, \\ Montpellier, France \\ 2Departments of Endodontic, University of Montpellier, Montpellier, \\ France

\begin{abstract}
Address for correspondence Camille Inquimbert, DMD. Departments of Dental Public Health, Faculty of Dentistry, University of Montpellier, Montpellier, France (e-mail: camille.inquimbert@umontpellier.fr).
\end{abstract}

Eur J Dent 2019;13:53-57

\begin{abstract}
Objective A large number of digital tools supporting students have emerged over recent years which are encouraged in tutoring. A study conducted at the University of Montpellier (France) among 3rd, 4th, and 5th year dentistry students aimed primarily to identify the type of pedagogical support the students preferred according to their discipline. The secondary aim was to evaluate the student satisfaction after establishing a new pedagogical support.

Materials and Methods A total of 165 questionnaires were completed. The main questions concerned pedagogical use of information technology and multimedia tools, choice of dentistry disciplines most justifying their use, and pedagogical gaps in these disciplines. Next, a program of pedagogical videos was developed for the most corresponding discipline. A satisfaction survey was finally conducted.

Results Nearly $95.7 \%$ of students found online classes and E-learning via the virtual learning environment useful, with the most requested type being video. Demand was stronger in conservative dentistry and endodontics (27\%), prosthetics (19\%), and periodontology (18\%). The most apprehended disciplines were endodontics in the 3rd year, endodontics and prosthetics in the 4th year, and prosthetics in the 5th year. Regarding satisfaction, $100 \%$ of students appreciated these videos and $99.4 \%$ considered they fulfilled expectations.

Keywords

- dental students

- digital

- endodontics

- learning

- pedagogical

Conclusion All students requested videos, especially for clinical subjects such as endodontics. With digital technology, our world is experiencing a technological revolution resulting in many daily life changes. With students evolving in a digitally saturated society, our ways of learning and teaching need rethinking. Digital technology can help improve learning effectiveness and develop pedagogical practices more adapted to today's students.
\end{abstract}

\section{Introduction}

Information and communication technologies (ICTs) in higher education are the subject of continual debate worldwide. Numerous studies spotlight digital development in learning in dentistry. ${ }^{1-7}$ According to several studies, some aspects of dentistry training appear to be the main sources of stress among dental students ${ }^{8-12}$ :
- The transition year when entering clinical practice is evaluated as the most stressful year due to fear of not treating competently and apprehension about patient contact.

- Entering clinical practice with patient "confrontation," a new situation for the student, is very anxietyprovoking. According to Manolova et al, marrying theory to clinical practice is difficult and stressful for French students. ${ }^{10}$
DOI https://doi.org/

10.1055/s-0039-1688526

ISSN 1305-7456.
License terms

(c) (1) $\ominus \circledast$ 
However, we found no study evaluating the form of teaching that students wished to benefit from, to enhance current learning, nor any validated questionnaire on pedagogical support preferences according to dentistry disciplines.

The aim of this two-step study was first to identify the type of pedagogical support the students preferred in each dental discipline and then to evaluate the impact and students' feelings toward this new pedagogical format in the discipline they deemed to need it most.

\section{Materials and Methods}

\section{Student Needs, Fears, and Expectations during Their Theoretical and Clinical Course}

In September 2016, a study was conducted at the Dentistry Faculty of the University of Montpellier. To construct this questionnaire targeted on the use of ICTs in dentistry and student needs, we proceeded iteratively to formulate progressively more precise questions. Several modifications were made after testing the questionnaire on five students of different years to evaluate the ease of comprehension and interpretation before launching the survey. Once validated, we decided to distribute this questionnaire to $3 \mathrm{rd}$, 4th, and 5th year classes to be sure of accessing all students: the 3rd year students may only access preclinical work, while the 4th and 5th year students are allowed to treat patients in a clinical environment.

The questionnaire included the following items:

- Would the provision of online classes or "E-learning" (via VLE) before compulsory lectures be useful to you?

- What type of support would most interest you during your classes and practical work? In which disciplines? We proposed three types of additional support:

- Proposition of clinical cases in photo format

- Distribution of clinical cases and/or treatments in video format

- Use of interactive software with self-test

- Have you already done Internet research to supplement your classes, watched videos on YouTube?

To detect a significant difference between the pedagogical supports, we calculated a minimum sample size. With a detected minimum difference of $20 \%$ between proposed choices, a power of $80 \%$, and a probability value of $5 \%$, a minimum of 160 students was calculated. This questionnaire was completed anonymously by 206 students.

\section{Creation and Establishment of the New Pedagogical Support}

After completion of this questionnaire, we established one of the new pedagogical supports that the students would like to have at disposal to enhance the current learning, that is, a video describing the different stages of root canal treatment. We could, therefore, test if the contribution of the new pedagogical tool would actually be perceived positively by the students of the 3 years.

To create the videos, we used a cold light lamp to illuminate the work area, a clamp to anchor the teeth, and photo and video material: two reflex cameras (Canon 7D and Nikon D7000).

We began the videographic shots according to the general steps of a root canal treatment:

- Access cavity preparation

- Endo-Z and Gates drills use

- Catheterization

- Work length determination

- Transition to rotary instrument

- Master cone adjustment.

Before performing video shots, the tooth specimens were cut into half and the root treatment was performed. The teeth were drilled carefully until we met the center of the apex and the root canal. The video editing was done with MacBook's "Final Cut Pro X." Four videos were created for endodontics. The editing time was up to 60 hours for a single video.

The first video concerned simplified endodontic treatment on a molar ( - Fig. 1); the second video, precurving of files; the third video, endodontic treatment on a premolar with two distinct camera shots ( - Fig. 2); and last, a clinical case highlighting ergonomics, work planning, and successful clinical treatment.

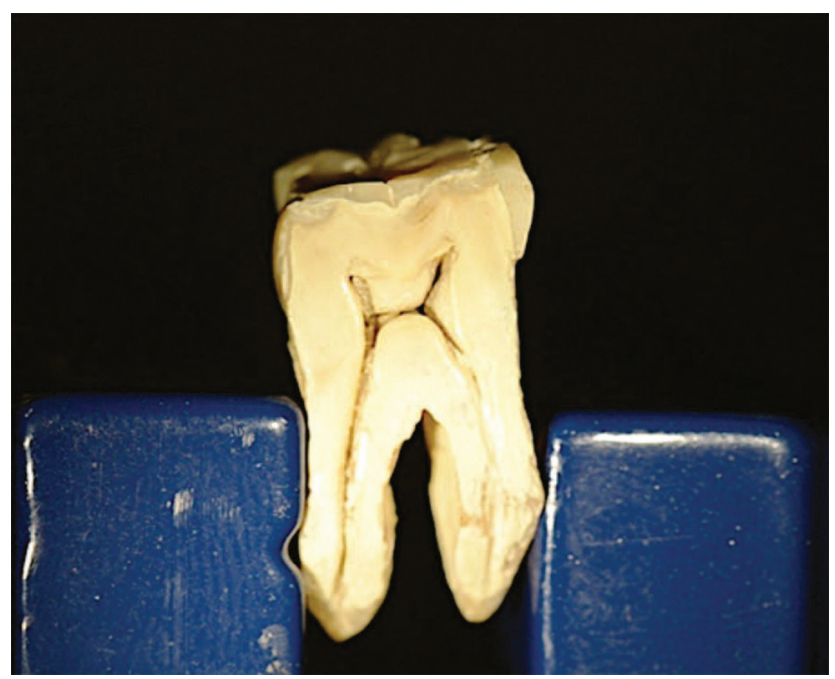

Fig. 1 Image of videoing molar.

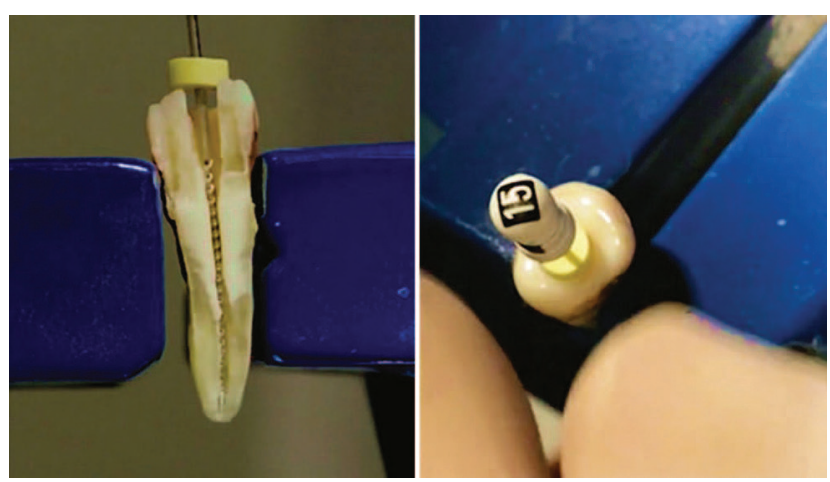

Fig. 2 Image of videoing premolar. 
Student Satisfaction with the New Pedagogical Support To evaluate the impact and students' feelings toward this new pedagogical format, a satisfaction questionnaire was devised. All videos were distributed during classes (to capture all students) and the questionnaires were distributed only to 3rd year students at the end of the class, according to the sample size calculation (statistical analysis). The questionnaire covered appreciation of videos, student satisfaction relative to expectations, need for other videos (and in which disciplines), and opinion on the effectiveness of this new support format for lectures and practical work. We also wanted to know when the students preferred viewing this type of video (on the Internet, during classes, or hands-on workshop).

Link to the three videos:

- Videos 1-3 Online content including video sequences viewable at: https://www.thieme-connect.com/products/ ejournals/html/doi/ 10.1055/s-0039-1688526.

\section{Statistical Analysis}

The calculation of the sample size indicated for the first questionnaire 150 subjects and for the satisfaction questionnaire 60 subjects.

All tests were validated with $p$-value fixed at 0.05 . We used Stata 14.1. software (StataCorp, College Station, Texas, United States) for the statistical analysis and Microsoft Excel 2010 (Microsoft Corporation, Redmond, Washington, United States) for graphics. Two tests were used:

- The Student's t-test allowed comparison between two groups.

- The chi-squared test allowed verification of a relationship between qualitative variables.

\section{Results}

\section{Students' Needs, Fears, and Expectations During their} Theoretical and Clinical Course

We obtained $80 \%$ participation with 165 questionnaires, compatible with the calculated minimum (160). The average age of respondents was 22.1 years, with $58.8 \%$ females versus $41.2 \%$ males. About $95.7 \%$ of students found the online classes or "E-learning" (via VLE) before compulsory lectures useful. Age, treated as a quantitative variable, was compared between the group who found the E-learning useful and the group who did not find the E-learning useful. Age was not significant in this response (Student's t-test, $p=0.94$ ). Gender and year of the study were not statistically significant (chi-squared test, $p=0.94$ and $p=0.27$, respectively). Video was a students' preferred choice, whatever the study year (chi-squared test, $p=0.04)$ (-Table 1). Females chose videos significantly more often than males (69.1 vs. $30.9 \%$, chi-squared test, $p=0.004$ ). More interest in video was manifested in prosthetics, periodontics, and endodontics, this result being independent of the year or gender ( - Fig. $\mathbf{3}$ ).

Student demands for course supplements concerned different disciplines (- Table 2):

- In conservative dentistry use of different restorative materials with their clinical application (53.7\%)

- Emergency treatment in endodontics was students' predominant concern whatever the year (64\% in 3rd year, $83 \%$ in 4 th year, and $85 \%$ in 5 th year)

- In periodontics, flap surgery was predominant at $80 \%$

- In oral medicine and surgery, performing complex avulsions was the most apprehended subject (63.9\%).

One can highlight the fact that $91.5 \%$ of students had already done Internet research at least once during their course, particularly looking at videos. This research had fulfilled expectations in $83.1 \%$ of cases and increased incrementally each study year (3rd year $79 \%$, 4 th year $96 \%$, and 5th year 100\%). Students researched videos to clarify and improve lesson comprehension and clinical practice (3rd year $83.6 \%$, 4th year $87.0 \%$, and 5th year $91.8 \%$ ). Prosthesis was researched the most, either on the Internet or sites such as "YouTube" (- Table 3 ).

Finally, the most dreaded discipline in the 3rd year, 1 year before clinical practice entrance, was endodontics ( - Fig. 4 ). Once students enter clinical practice, two disciplines principally concerned the endodontics and prosthesis ( - Table 4 ).

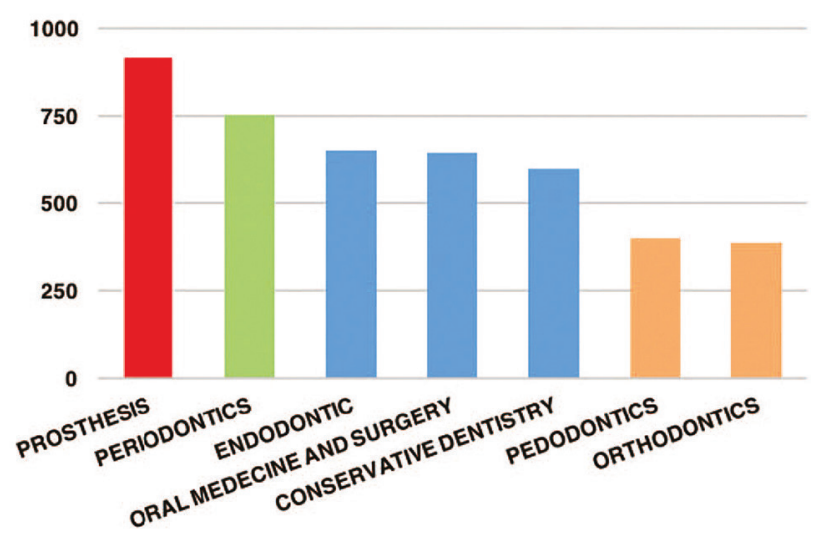

Fig. 3 Video support need for each disciplines.

Table 1 Breakdown of pedagogical support choices according to the study year

\begin{tabular}{|l|l|l|l|l|}
\hline & 3rd year & 4th year & 5th year & Total \\
\hline Pictures (\%) & $23(34.8)$ & $14(29.2)$ & $16(32.6)$ & $53(32.5)$ \\
\hline Videos (\%) & $25(37.9)$ & $22(45.8)$ & $21(42.9)$ & $68(41.7)$ \\
\hline Software (\%) & $18(27.3)$ & $12(25.0)$ & $12(24.5)$ & $42(25.8)$ \\
\hline Total (\%) & $66(100)$ & $48(100)$ & $49(100)$ & $163(100)$ \\
\hline
\end{tabular}


Table 2 Most requested topics for video according to the discipline

\begin{tabular}{|l|l|}
\hline Disciplines & $\mathbf{n}(\%)$ \\
\hline Conservative dentistry (\%) & \\
\hline Caries diagnosis & $74(45.1)$ \\
\hline The use of different restorative materials & $88(53.7)$ \\
\hline Endodontics (\%) & \\
\hline Access cavity & $34(20.5)$ \\
\hline The management of emergencies & $126(75.9)$ \\
\hline Prosthesis (\%) & \\
\hline Crown removal techniques & $46(27.5)$ \\
\hline Post and core techniques & $103(61.7)$ \\
\hline Periodontology (\%) & \\
\hline Charting & $30(17.8)$ \\
\hline Flap surgery & $135(80.4)$ \\
\hline Oral surgery (\%) & \\
\hline Inferior alveolar nerve block techniques & $59(34.3)$ \\
\hline Tooth extraction (unerupted, wisdom) & $110(64.0)$ \\
\hline Orthodontics (\%) & $65(43.6)$ \\
\hline Cephalometric & $55(39.6)$ \\
\hline Space maintainer & \\
\hline Pedodontics (\%) & \\
\hline Pulpotomy & \\
\hline Pediatric crown & \\
\hline
\end{tabular}

Table 3 Research of course supplements on Internet and YouTube according to the discipline

\begin{tabular}{|l|l|l|}
\hline Course supplement & Internet (\%) & YouTube (\%) \\
\hline None & $34(9.6)$ & $20(9.6)$ \\
\hline Conservative dentistry & $43(12.1)$ & $33(15.9)$ \\
\hline Endodontics & $55(15.5)$ & $26(12.5)$ \\
\hline Prothesis & $67(18.9)$ & $41(19.6)$ \\
\hline Periodontology & $64(18.2)$ & $39(18.8)$ \\
\hline Oral surgery & $43(12.1)$ & $44(21.2)$ \\
\hline Orthodontics & $24(6.8)$ & $2(1.0)$ \\
\hline Pedodontics & $24(6.8)$ & $3(1.4)$ \\
\hline
\end{tabular}

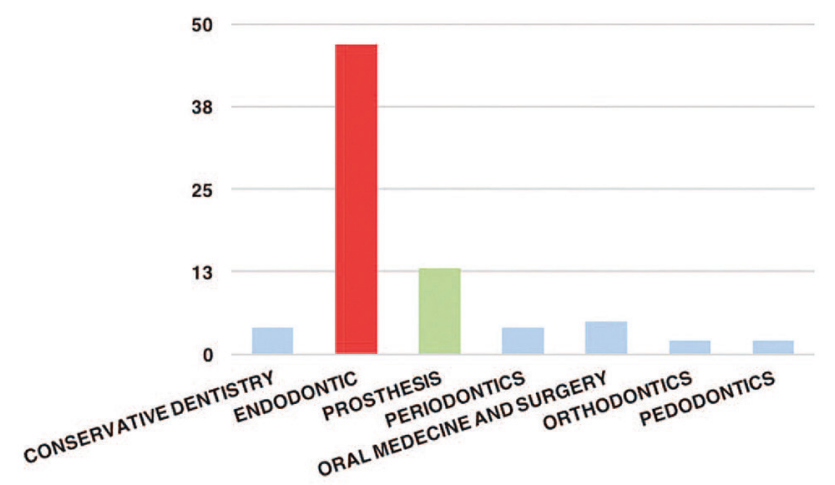

Fig. 4 Breakdown of most apprehended 3rd year disciplines.

It is clear from this first questionnaire that students demanded new pedagogical supports for learning: video was the most demanded over the three participating years.

\section{Student Satisfaction Regarding New Video Support}

We obtained 71 questionnaires, a 100\% response rate from all 3rd year students. One-hundred percent of students appreciated the video distributed, and it fulfilled expectations for all. Concerning the time, when the students preferred viewing this type of video, no particular time was predominantly preferred, but the first choice was video distribution during hands-on workshop.

All students wanted other videos to aid comprehension of lectures and clinical practice. Certain students shared their satisfaction in the free commentary section. It appears that students appreciated the concise and visual nature of this video. The most prevalent comments resembled the following: "very useful for summarizing and enabling the comprehension which a class does not produce initially" and "video is great, particularly cross-sectional visual of the tooth aids comprehension."

\section{Discussion}

The main aim of this study was to analyze the student needs for new pedagogical supports. Looking at the results of this qualitative analysis of the questionnaires, it emerges that there was a strong need for supplementary support for lectures and practical work: video was the most requested tool. What is impeding teachers today in digital application

Table 4 Most apprehended disciplines according to the year

\begin{tabular}{|l|l|l|l|}
\hline Most apprehended discipline & 3rd year (\%) & 4th year (\%) & 5th year (\%) \\
\hline Conservative dentistry & $4(5.2)$ & $0(0.0)$ & $2(5.7)$ \\
\hline Endodontics & $47(61.0)$ & $22(40.0)$ & $6(17.1)$ \\
\hline Prothesis & $13(16.9)$ & $21(38.2)$ & $22(62.9)$ \\
\hline Periodontology & $4(5.2)$ & $6(10.9)$ & $4(11.4)$ \\
\hline Oral surgery & $5(6.5)$ & $6(10.9)$ & $1(2.9)$ \\
\hline Orthodontics & $2(2.6)$ & $0(0.0)$ & $0(0.0)$ \\
\hline Pedodontics & $2(2.6)$ & $0(0.0)$ & $0(0.0)$ \\
\hline
\end{tabular}


in our faculty is the lack of materials and time and the technical complexity required for video production. Despite that, most of the teachers were persuaded that educational technologies such as video provided better visualization and could improve health professions student learning outcomes. ${ }^{13}$ Many studies in the medical field show the positive effect of videographic tools. ${ }^{14,15}$ In 2007, a study by Reynolds et al highlighted the growing appeal of teaching ICT with students. ${ }^{6}$ Reissmann et al also found the same results in a German dental school. ${ }^{7}$ The results of the present study confirm the potential of these new technologies together with the utmost interest of the students.

An evolution of student needs over the years was evident. It appears that progressing through the clinical curriculum, students find their bearings for performing endodontic treatment. Conversely, prosthesis remains a dreaded discipline. Establishing a diagnosis and management of multidisciplinary cases remains complex notions throughout the clinical years. This study sample did not include all students in the faculty: 2nd and 6th years were left out. We considered that 2 nd year students are just beginning theory and do not have the hindsight to be objective with this questionnaire and 6th year only have intern clinical practice which makes it difficult to question the whole cohort. The selection bias was weak, even nonexistent, because we questioned every student from each year of the study concerned with the study topic.

Although external validation of the study is not established, given that it depends on the type of teaching in place, the trends concerning observed students' wishes seem logical: 3rd year students, the most inexperienced, requested these new pedagogical tools the most. Students of other years appreciated them, but to a lesser degree. The usual biases found in self-administered questionnaires concern honesty regarding personal questions. Knowing that these questionnaires are anonymous, this bias is expected to be minimal and students had no reason to falsify their responses since this questionnaire was aimed at improving their learning.

\section{Conclusion}

Analysis of the first questionnaire enabled determination of the most requested pedagogical support to assist understanding of lectures and practical work: video. Another important result was that endodontics was the most apprehended discipline when entering clinical practice. This result was accompanied by another finding: most students had already done Internet research at least once during their course and the most researched disciplines were prosthesis, periodontics, and endodontics. Finally, all respondents of the satisfaction survey, having watched the videos created, appreciated this "new" pedagogical support, and for all students, this fulfilled their expectations.
The use of more targeted didactic tools such as clear and precise videos might enable students to better understand theory and diminish fears for their clinical practice debut and the remainder of their course.

\section{Financial Support and Sponsorship}

Nil.

\section{Conflicts of Interest}

None declared.

\section{References}

1 Edrees HY, Ohlin J, Ahlquist M, Tessma MK, Zary N. Patient demonstration videos in predoctoral endodontic education: Aspects perceived as beneficial by students. J Dent Educ 2015;79(8):928-933

2 Dhulipalla R, Marella Y, Katuri KK, Nagamani P, Talada K, Kakarlapudi A. Effect of 3D animation videos over 2D video projections in periodontal health education among dental students. J Int Soc Prev Community Dent 2015;5(6):499-505

3 Miller CJ, Metz MJ. Can clinical scenario videos improve dental students' perceptions of the basic sciences and ability to apply content knowledge? J Dent Educ 2015;79(12):1452-1460

4 Maggio MP, Hariton-Gross K, Gluch J. The use of independent, interactive media for education in dental morphology. J Dent Educ 2012;76(11):1497-1511

5 Smith W, Rafeek R, Marchan S, Paryag A. The use of video-clips as a teaching aide. Eur J Dent Educ 2012;16(2):91-96

6 Reynolds PA, Rice S, Uddin M. Online learning in dentistry: the changes in undergraduate perceptions and attitudes over a four year period. Br Dent J 2007;203(7):419-423

7 Reissmann DR, Sierwald I, Berger F, Heydecke G. A model of blended learning in a preclinical course in prosthetic dentistry. J Dent Educ 2015;79(2):157-165

8 Bourassa M, Baylard JF. Stress situations in dental practice. J Can Dent Assoc 1994;60(1):65-67, 70-71

9 Zakher R, Bourassa M. Stress factors and coping strategies in the dental profession. J Can Dent Assoc 1992;58(11):905-906, 910-911

10 Manolova MS, Stefanova VP, Panayotov IV, et al. Perceived sources of stress in fifth year dental students--a comparative study. Folia Med (Plovdiv) 2012;54(2):52-59

11 Sanders AE, Lushington K. Effect of perceived stress on student performance in dental school. J Dent Educ 2002;66(1):75-81

12 Alhajj MN, Khader Y, Murad AH, et al. Perceived sources of stress amongst dental students: a multicountry study. Eur J Dent Educ 2018;22(4):258-271

13 Chi DL, Pickrell JE, Riedy CA. Student learning outcomes associated with video vs. paper cases in a public health dentistry course. J Dent Educ 2014;78(1):24-30

14 Reed S, Shell R, Kassis K, et al. Applying adult learning practices in medical education. Curr Probl Pediatr Adolesc Health Care 2014;44(6):170-181

15 Pinsky LE, Wipf JE. A picture is worth a thousand words: practical use of videotape in teaching. J Gen Intern Med 2000;15(11):805-810 